\title{
Base de datos de ADN e intimidad personal, una propuesta al Derecho Genético peruano
}

\section{DNA Database and Personal Privacy, a Proposal to the Peruvian Genetic Law}

Raúl Ángel Quintanilla Revatta* http://dx.doi.org/10.21503/lex.v13i16.867

\footnotetext{
Biólogo forense y perito criminalista de la Policía Nacional del Perú. Abogado, magíster en Ciencias Penales y doctor en Derecho y Ciencia Política de la Universidad Nacional Mayor de San Marcos; maestrista en Criminalística de la Universidad Nacional Federico Villarreal. E-mail: rangel7000@gmail.com
} 


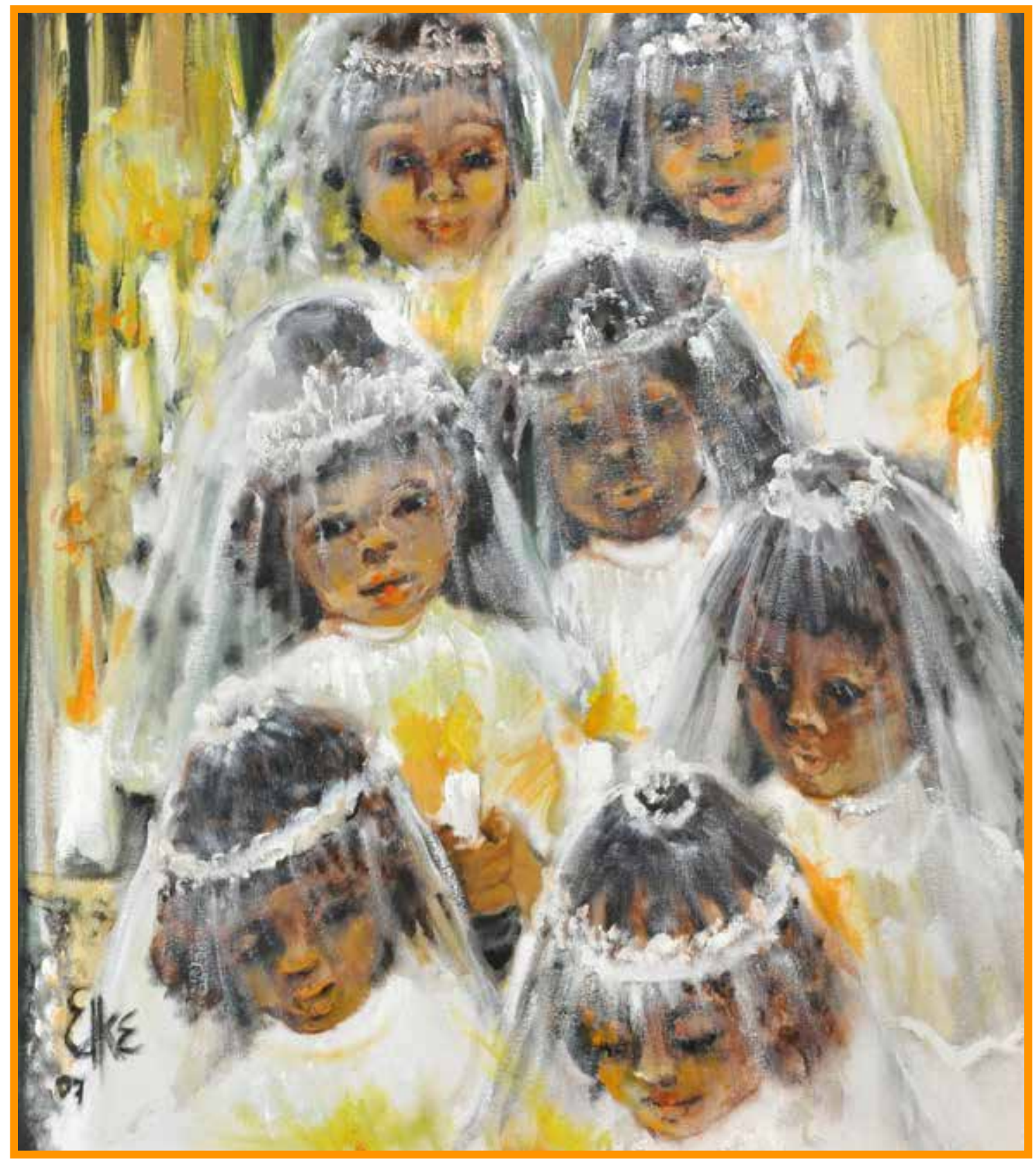

Primera Comunión. Serie "Fiesta de fe". Óleo $(70 \times 70 \mathrm{~cm})$, año 2 007. Elke McDonald 


\section{RESUMEN}

Este artículo plantea la importancia de un cotejo automatizado de huellas de ADN dubitadas halladas en la escena del crimen con aquellas indubitadas almacenadas en una base de datos de $\mathrm{ADN}$, lo que implica una rápida resolución de casos donde se cuenta con evidencia genética, con el consecuente ahorro de recursos, produciendo un medio de prueba que refuerza el modelo propuesto por el nuevo proceso penal, cuyos principios rectores propenden un proceso fluido a través de plazos definidos. Pero la implementación de este sistema automatizado de identificación genética requiere de una ley peruana de creación de una base de datos de ADN de uso forense que respete derechos fundamentales consagrados en la Constitución, como la intimidad personal. Ello se garantiza pues este sistema biométrico solo implica la creación de un registro de huellas genéticas digitalizadas de ADN no codificante, es decir, de aquel tipo de $\mathrm{ADN}$ que no puede dilucidar más información personal que aquella que solo sirva única y exclusivamente para fines de identificación.

Palabras clave: ácido desoxirribonucleico, base de datos de $A D N$ forense, criminalística, derecho genético, intimidad personal.

\section{ABSTRACT}

This article sets out the importance of an automated comparison of samples of DNA fingerprints which are controvertible, found at the crime scene against the incontrovertible stored in a forensic DNA data bank, which implies a quick resolution of cases where exist genetic evidence, with consequent saving resources, producing a type of evidence that reinforces the proposed model by the new criminal process, whose basic principles look for a continue process through defined deadlines. However, the implementation of this automated system of genetic identification requires a Peruvian law that provides a framework for the creation of the forensic DNA data bank, which respects fundamental rights enshrined in the Constitution, such as personal privacy. This is guaranteed because this biometric system only involves the creation of a record of non-coding DNA genetic fingerprints scanned, i.e., the kind of DNA that cannot elucidate more personal information than one that only serves exclusively for identification purposes.

Key words: deoxyribonucleic acid, forensic DNA data bank, criminalistics, genetic right, personal privacy. 

$Y$ vosotros, que pretendéis entender de justicia, ¿cómo podréis hacerlo si no miráis todos los hechos en la plenitud de la luz?

Gibran Khalil Gibran

\section{INTRODUCCIÓN}

La humanidad se enfrenta a un salto cuántico hacia adelante, se enfrenta a la más profunda conmoción social y reestructuración creativa de todos los tiempos. Sin advertirlo claramente, estamos dedicados a construir una civilización extraordinariamente nueva. ${ }^{1}$ Ese cambio sin parangón se denomina revolución genética, pues del mismo modo que manipulábamos metales y plásticos hoy fabricamos materiales vivos; ella está convocada a transformar toda la estructura social, política y jurídica de la humanidad, pues está produciendo cambios en campos tan diferentes como la agricultura, la reproducción, las terapias, la minería, la energética, la oceanografía, la alimentación, y como consecuencia de todas ellas, la legislación, la jurisprudencia, la ética y la moral.

Esta revolución biológica que atraviesa la humanidad con todo ese abanico de posibilidades genéticas ha alcanzado también a la criminalística, proporcionando una respuesta a la problemática de la identificación humana con fines forenses, es decir, se plasma de manera tangible una colaboración eficaz de la biotecnología a la administración de justicia penal que hasta no hace mucho carecía de un mecanismo técnico-científico altamente confiable que se constituya en un medio de prueba irrefutable; esa expectativa hoy es cubierta por la "Huella del ADN" o "DNAFingerPrints".

Al aplicarse la prueba del ADN en la investigación criminal, se la comenzó a llamar Genética Forense o Genética Criminalística, siendo esta el estudio de la versatilidad de la genética humana utilizada en la resolución de procesos penales, analizando vestigios biológicos hallados en la escena del crimen que, luego de una idónea colección de $A D N$ y correcta cadena de custodia, ${ }^{2}$ se trata de cotejar con perfiles genéticos de posibles participes, alcanzando gran importancia para la identificación humana en los delitos con evidencias

\footnotetext{
Alvin Toffler. La tercera ola. Bogotá D. C.: Plaza \& Janés, 1981.

Raúl Quintanilla R. La prueba genética en el proceso penal, su idónea colección de ADN y cadena de custodia en la investigación criminal y sus implicancias jurídicas en el Nuevo Código Procesal Penal. Ponencia presentada al XX Congreso Latinoamericano, XII Iberoamericano y V Nacional de Derecho Penal y Criminología. Lima: Universidad Nacional Mayor de San Marcos, 2008.
} 
genéticas. Así, el ADN se convirtió en un poderoso instrumento de la investigación del delito para la detección de criminales, viéndose con el paso del tiempo necesaria la automatización de estos cotejos, por lo que se crearon en muchos países Bases de Datos de $A D N$ de uso forense ( $B D-A D N-F)$ para fines de investigación criminal, que se utilizan para realizar cotejos computarizados de un perfil dubitado con otros indubitados en un tiempo mínimo, para luego ser consultados por la autoridad competente, buscando no interferir con los derechos constitucionales de las personas, a pesar de que por su aplicación reciente, varios de estos países carecen todavía de una legislación clara en el tema del ADN. ${ }^{3}$

Muchos de los delitos que quedan sin resolver, porque en un momento determinado no hay un sospechoso, pueden ser resueltos, incluso años después de que se hayan cometido, gracias al desarrollo de una base de datos de $\mathrm{ADN}$ de uso forense. Esta BD-ADN-F pretende colaborar en la resolución de casos criminales permitiendo la comparación automatizada de perfiles genéticos procedentes de diversas fuentes: indicios no identificados de la escena del crimen, muestras de referencia de sospechosos y muestras de referencia de víctimas. Tras las comparaciones pertinentes, y con un número suficiente de muestras analizadas, se puede comprobar si una persona (imputado o procesado) ha dejado indicios biológicos en más de una escena criminal o sobre más de una víctima. Este es uno de los medios más eficaces de controlar a los criminales en serie y a delincuentes reincidentes, algo muy típico en casos de violaciones de la libertad sexual.

En el momento actual existen múltiples problemas de tipo técnico-científico, económicosocial y jurídico-legal para llevar a cabo un proyecto de banco genético general para toda la población, por lo que no se plantea su elaboración.

Todo esto conlleva a cuestionar, desde la perspectiva de la biotecnología, qué tan eficaz es el sistema penal en el Perú en lo que respecta al cruce de información que conlleve a una eficiente investigación del delito a partir del análisis de $\mathrm{ADN}$, el cual hace ya más de quince años se viene utilizando en nuestro país como método de identificación en el ámbito forense de instituciones del Estado. Dicha prueba se ha convertido en una herramienta imprescindible tanto en el ámbito penal como en materia de filiación. Esta realidad plantea la necesidad de crear en nuestro país una BD-ADN-F, con la que países vecinos ya cuentan, y con la convicción de que solo así podrá brindar a sus procesos penales el aval y sustento informático que es necesario para dar fuerza y fluidez a la homologación genética que resolvería muchos casos, como sucede en los países desarrollados.

3 Viviana Bernath. La identidad. Historias reales del ADN. Buenos Aires: Grupo Editorial Planeta, 2007. 
Dicha base de datos requiere de un sistema rector de BD-ADN-F para su manejo y regulación, sustentado por una legislación especial que absuelva las siguientes interrogantes: ¿cómo se deben obtener los datos?, ¿cuáles deben ser las condiciones de almacenamiento de datos?, ¿qué criterios se deben considerar al cruzar los datos?, ¿cómo se acreditan los laboratorios que realizan el análisis?, ¿se deben considerar solo algunos delitos o todos en general?, ¿para imputados o solo para condenados?, ¿qué institución debe administrar la BDADN-F?, ¿quién puede acceder a él y bajo qué condiciones?, ¿qué derechos fundamentales pueden resultar afectados por la conservación de muestras biológicas? Todo lo anterior pensado en los derechos del titular de la información genética. ${ }^{4}$

De acuerdo a todo lo expresado, en nuestro país, la implementación de este Sistema Automatizado de Identificación Genética requerirá de una Ley Peruana de Creación de $B D-A D N-F$ que deberá absolver las interrogantes planteadas en el ítem precedente. Dicha propuesta legislativa no debe contradecir la vigencia y respeto de las garantías individuales y derechos fundamentales, como la intimidad personal, pues solo implica la creación de un Registro de Huellas Genéticas Digitalizadas de ADN No Codificante, es decir, de aquel tipo de ADN que no puede dilucidar más información personal que aquella que sirva única y exclusivamente para fines de identificación.

Resumiendo todo lo dicho, la doctrina moderna señala que para lograr la consolidación del Moderno Proceso Penal, el sistema que lo operativiza debe apoyarse en tecnologías forenses de vanguardia, las cuales son base de la criminalística. ${ }^{5}$ Ante esta realidad cabe el siguiente planteamiento: ¿Cómo se puede dinamizar la identificación humana por ADN en los delitos con evidencias biológicas en el contexto de un proceso penal acusatorio moderno que pretenda optimizar la investigación preparatoria, si no se desarrolla de manera cabal una genética forense peruana con criterios de eficiencia y oportunidad? Se pretende demostrar en la presente investigación que esta falencia es una de las causas principales de la pérdida de eficacia de la justicia penal en el Perú en la resolución de delitos graves, donde se producen evidencias biológicas, y que si no se solucionan se seguirá ofreciendo a la sociedad peruana un medio ineficaz de resolución de crímenes que tienen gran relevancia social, con la consiguiente sensación de inseguridad.

4 Paola Paz K. Problemática legal generada por la falta de regulación respecto al manejo de bases de datos genéticos de uso forense. Tesis para optar el título de Magíster en Biociencias y Derecho. Bogotá D.C.: Universidad Nacional de Colombia, 2012.

5 Raúl Quintanilla R. Factores de la inspección criminalistica que determinan la calidad de la investigación de la escena del crimen y su importancia en el nuevo modelo procesal penal peruano. Tesis para optar el grado de Magíster. Lima: Universidad Nacional Mayor de San Marcos, Escuela de Postg rado, Unidad de Post Grado en Derecho, 2011. 


\section{METODOLOGÍA}

\section{TIPO DE INVESTIGACIÓN}

Conviene anotar que los tipos de investigación difícilmente se presentan puros; generalmente se combinan entre sí y obedecen sistemáticamente a la aplicación de la investigación. La elección o selección del tipo de investigación depende, en alto grado, del objetivo del estudio del problema de investigación y de las hipótesis que se formulen en el trabajo que se va a realizar, así como de la concepción epistemológica y filosófica de la persona o del equipo investigador. ${ }^{6}$

Según Zorrilla, ${ }^{7}$ la investigación se clasifica en cuatro tipos: básica, aplicada, documental, de campo o mixta. Estas dos primeras clases de investigación que menciona Zorrilla se elaboran tomando como criterio el grado de abstracción del trabajo, y para otros, según el uso que se pretende dar al conocimiento, pero siempre la investigación aplicada guardará íntima relación con la básica, pues depende de los descubrimientos y avances de la investigación básica y se enriquece con ellos, pero se caracteriza por su interés en la aplicación, utilización y consecuencias prácticas de los conocimientos.

La presente investigación es de tipo aplicada, ya que busca conocer para modificar y mejorar el trabajo del perito criminalista en la identificación genética, es decir, se pretende con un sentido de pragmatismo optimizar la genética forense nacional con el cotejo automatizado de huellas de $\mathrm{ADN}$, para así incrementar la eficiencia de la investigación preparatoria del nuevo proceso penal cuando se cuenten con indicios biológicos.

Otros autores como Babbie $^{8}$ y Selltiz identifican tres tipos de investigación: exploratoria, descriptiva y explicativa, así como Dankhe ${ }^{10}$ propone cuatro tipos de estudios: exploratorios, descriptivos, correlacionales y experimentales. Sin embargo, hay quienes prefieren denominar estos últimos como estudios explicativos en lugar de experimentales, pues consideran que existen investigaciones no experimentales que pueden aportar evidencias para explicar las causas de un fenómeno. Se puede decir que esta clasificación usa como criterio lo que se pretende con la investigación, sea explorar un área no estudiada antes, describir una situación o pretender una explicación del mismo.

Roberto Hernández Sampieri presenta una tipología de investigaciones en ciencias sociales. La tipología se refiere al alcance que puede tener una investigación científica.

6 César Bernal T. Metodología de la investigación para administración, economía, humanidades y ciencias sociales. Bogotá D. C.: Pearson Educación, 2010.

S. Zorrilla y M. Torres. Guia para elaborar la tesis. México: Editorial McGraw-Hill, 1993.

8 E. R. Babbie. The practice of social research. California: Wadsworth, 1979.

9 C. Selltiz; M. Jahoda; M. Deutsch y S. W. Cook. Métodos de investigación en las relaciones sociales. Madrid: Ediciones Rialp, 1965.

10 G. L. Dankhe. Investigación y comunicación. México: McGraw-Hill, 1986. 
La tipología considera cuatro clases de investigaciones: exploratorias, descriptivas, correlacionales y explicativas. Las investigaciones explicativas son más estructuradas que las demás clases de estudios y de hecho implican los propósitos de ellas (exploración, descripción y correlación), además de que proporcionan un sentido de entendimiento del fenómeno al que hacen referencia. ${ }^{11}$

En el mismo orden de ideas que el ítem precedente en lo que se refiere a los tipos de investigación, Ramón Ramírez Erazo apunta concomitantemente que existen cuatro tipos de investigación: la exploratoria, la descriptiva, la correlacional y la causal explicativa. ${ }^{12}$

La presente investigación es de tipo explicativa porque pretende explicar la trascendencia de los factores más idóneos de la identificación genética para obtener una mayor eficacia en los procesos que conllevan a una fehaciente identificación humana a través de la Prueba del ADN.

\section{DISEÑO DE INVESTIGACIÓN}

Kerlinger ${ }^{13}$ dice que "generalmente se llama diseño de investigación al plan y a la estructura de un estudio". Es el plan y estructura de una investigación concebidas para obtener respuestas a las preguntas de un estudio. El diseño señala la forma de conceptuar un problema de investigación y la manera de colocarlo dentro de una estructura que sea guía para la experimentación (en el caso de los diseños experimentales) y de recopilación y análisis de datos.

En el enfoque cuantitativo se utiliza el diseño para analizar la certeza de la hipótesis formulada en un contexto en particular o aportar evidencias de los lineamientos de investigación (si no hubiera hipótesis).

En estudios cualitativos, se puede o no concebir un diseño, se sugiere que sí se haga, pero la implementación de los mismos se vuelve más flexible, lo que no significa caos o improvisación. El investigador puede elegir y desarrollar uno o más diseños para iniciar previamente la recolección de datos. En otro momento realiza una primera inmersión en el campo y después analiza qué diseño de investigación le conviene para recolectar la información requerida.

En cuanto a la organización de los diseños de investigación, Hernández ${ }^{14}$ nos propone la siguiente clasificación:

\footnotetext{
Roberto Hernández S. Metodología de la investigación. Bogotá D.C.: McGraw-Hill, Interamericana, 1997.

Ramón Ramírez E. Proyecto de investigación. Cómo se hace una tesis. Lima: Fondo Editorial AMADP, 2010.

F. Kerlinger. Enfoque conceptual de la investigación del comportamiento. México: Interamericana, 1990, p. 83.

$14 \quad$ Ibid. p. 187
} 
- Diseños experimentales

Estudio en el que se manipulan intencionalmente una o más variables independientes (supuestas causas) para analizar las consecuencias que la manipulación ha generado sobre una o más variables dependientes (supuestos efectos) dentro de una situación de control del investigador.

- Diseños no experimentales

Se define a las investigaciones que se realizan sin manipular deliberadamente variables. Lo que se hace es observar fenómenos tal y como se dan en su contexto natural, para después analizarlos.

Estos diseños se clasifican teniendo en cuenta su dimensión temporal o el número de momentos o puntos en el tiempo, en los cuales se recolectan los datos, y así tenemos diseño transeccional y diseño longitudinal.

Podemos afirmar que, de acuerdo a los investigadores mencionados en el presente acápite, la investigación según el período de tiempo en que se desarrolla puede ser de tipo horizontal o longitudinal cuando se extiende a través del tiempo dando seguimiento a un fenómeno, o puede ser vertical o transversal cuando apunta a un momento y tiempo definido.

De acuerdo a lo señalado en los ítems precedentes, podemos decir que la presente investigación tiene un diseño no experimental, y como características de tipo de investigación, ser un estudio aplicado, explicativo, sociojurídico, porque responderá la causa de los hechos estudiados, y longitudinal por la relación de hechos a través de varias unidades de tiempo en el medio social (Sexenio 2006-2012).

\section{POBLACIÓN}

La población de esta investigación estuvo conformada no solo por documentos a los cuales se les extrajo la información necesaria para el estudio de las variables, específicamente de leyes, textos doctrinales, jurisprudencias, textos provenientes de páginas de consulta en Internet; sino también por todos aquellos factores que intervienen en la genética forense nacional y determinan la calidad de la identificación genética en el Perú.

El presente trabajo cubre como universo general dos (02) aspectos importantes de la investigación jurídico-social que desarrollamos a través del personal de especialistas de:

1. Los laboratorios forenses de entidades peruanas públicas que constitucionalmente deben brindar el apoyo cientifico a las diligencias preliminares de la investigación preparatoria del Código Procesal Penal del 2004 que realizan la obtención de la huella del ADN.

2. Las instituciones forenses oficiales de paises líderes en genética criminalistica que realizan 
una gestión eficiente en el cotejo automatizado de perfiles genéticos en una BD-ADN-F en el apoyo a la investigación criminal de sistemas penales acusatorios modernos.

\section{SELECCIÓN DE MUESTRA}

Respecto a la muestra seleccionada en los DOS (02) niveles del universo, tanto en el Perú como en el extranjero, se eligió una muestra no probabilística determinada en base al planteamiento del problema, hipótesis y alcance de sus contribuciones.

La selección de las unidades de análisis depende de las características de la población. Implica un juicio personal del investigador por la especialidad o la naturaleza del objeto de estudio. Se recopilan datos de las unidades a investigar más apropiadas. ${ }^{15}$

Refiriéndose a la unidad de análisis, se destacó del universo solo aquellos que son determinantes dentro del contexto de aplicación de la prueba del $\mathrm{ADN}$ a la identificación humana con fines forenses. Para el caso se seleccionaron como muestras las dos (02) únicas instituciones estatales que desarrollan genética forense en el país (Policía Nacional y Ministerio Público) a través del estudio de sus factores humanos (peritos criminalistas), factores tecnológicos (equipos forenses) y factores externos (medioambientales), que en su conjunto deciden la calidad de la genética forense peruana, siendo los peritos forenses de estas instituciones:

1. Laboratorio de Biologia Molecular y $A D N$ de la Dirección Ejecutiva de Criminalística (POLICÍA NACIONAL DEL PERÚ).

2. Laboratorio de Biología Molecular y Genética del Instituto de Medicina Legaly Ciencias Forenses (MINISTERIO PÚBLICO).

El estudio en estas entidades se realizó dentro del contexto de aquellos hechos más relevantes de la investigación del delito efectuada de manera técnica y científica ocurridos en la ciudad de Lima, como preparación para la puesta en vigencia del nuevo modelo procesal penal acusatorio, adversarial y garantista que propende el Decreto Legislativo $\mathrm{N}^{\circ}$ 957 (Código Procesal Penal del 2004), que ya es aplicado en la ciudad capital en delitos de corrupción de funcionarios desde el 01 de abril de 2011, y que entrará en vigor para todos los demás delitos el 2016, buscando así modernizar la justicia penal peruana.

En cuanto a las instituciones forenses oficiales que realizan a nivel internacional una gestión eficiente de la BD-ADN-F en la identificación genética informatizada para apoyar la investigación criminal en modernos sistemas penales acusatorios, de una población representativa de dieciséis (16) países contactados (Estados Unidos, Reino Unido, Portugal,

15 Ramón Ramírez E. Loc. cit. 
España, Francia, Australia, Argentina, Chile, Uruguay, Brasil, Colombia, Venezuela, Panamá, Costa Rica, México y Canadá) se tomaron como muestra a cinco (05) países que fueron los que apoyaron la investigación con la opinión especializada de peritos genetistas en Australia, Colombia, Chile, España y México. Dichas instituciones extranjeras que administran con éxito la BD-ADN-F, consideradas como muestra representativa en la presente investigación científica, fueron las siguientes:

1. Equipo de Forenses de la Australian Federal Police, Canberra, ACT-AUSTRALIA.

2. Laboratorio de Genética Forense de la Dirección de Investigación Criminal e Interpol de la Policía Nacional de Colombia (DIJIN) - COLOMBIA.

3. Laboratorio de Genética Forense del Dpto. de Criminalistica de Carabineros (LABOCAR) - CHILE

4. Laboratorio de Genética Forense de la Comisaría General de Policía Científica del Cuerpo Nacional de Policía, Sede Madrid - ESPAÑA.

5. Laboratorio de Genética Forense de la Procuraduría General de Justicia del Estado de Guanajuato - MÉXICO.

\section{RESULTADO}

De acuerdo al desarrollo de la investigación y de acuerdo a la información procesada obtenida de fuentes primarias y secundarias, se puede apreciar que el presente trabajo abarca un tema primordial en el contexto de reforma del sistema procesal penal de nuestro país, y creemos posible presentar ya algunos resultados que nos permiten hacer diversas recomendaciones para desarrollar varias estrategias a ser incluidas como la necesidad de implementar en el Perú, una BD-ADN de uso criminal, bajo el contexto de un nuevo modelo procesal acusatorio, adversarial y garantista que presenta la necesidad de contar con medios probatorios fidedignos pero sobre todo eficaces.

Esta eficacia se requiere especialmente en el caso de aquellos delitos que revisten gravedad, donde se aprecia que es indispensable un dinamismo que permita una investigación criminal no solo de calidad, sino sobre todo con criterio de oportunidad, para lo cual, se analizó aquellos factores imprescindibles en todo proceso de identificación humana con fines forenses, resumidos en tres factores fundamentales (humano, tecnológico y externo), los cuales deben empoderar a una genética forense nacional que brinde un apoyo fluido al proceso penal, y permitan tener una mejor visión de la coyuntura 
reformadora que vivimos en el sistema penal. Estos resultados fueron obtenidos en un estudio interinstitucional de las dos entidades tutelares del Estado comprometidas constitucionalmente en la investigación del delito (Policía Nacional y Ministerio Publico).

Asimismo, para validar la hipótesis planteada con la realidad, se ha realizado la correspondiente contrastación con países que se encuentran a la vanguardia de la genética forense mundial y que cuentan, desde hace ya algún tiempo con una BD- ADN-F, y a los cuales se les requirió opinión especializada, información que corroboró la hipótesis propuesta.

Luego de haber descrito los resultados de la investigación, sobre la necesidad de implementar una BD-ADN de uso criminal en el Perú, acompaña a este análisis la evaluación de los factores que determinan la calidad de la genética forense nacional, la cual redunda de manera importante en la aplicación del moderno modelo procesal penal; el presente ítem comprende la discusión de los hallazgos. "La finalidad principal de la discusión es mostrar las relaciones existentes entre los hechos observados. (...) y lo más que uno podía hacer será arrojar un poco de luz sobre la parcela de la verdad". ${ }^{16}$

Del estudio analítico-sintético del presente trabajo de investigación se observa que son fundamentalmente tres los factores de la genética forense nacional que determinan la calidad de la identificación humana por $\mathrm{ADN}$ con fines forenses, siendo en orden de importancia los siguientes:

- Factor humano.

- Factor tecnológico.

- Factor externo.

Estos factores, de manera concomitante van a poseer una influencia significativa en la labor del perito genetista durante el desarrollo de sus actividades funcionales en el proceso de identificación genética.

De los resultados también se puede evidenciar que en nuestro país del año 2006 al 2010 hubo un aumento del número de casos forenses que han requerido exámenes genéticos para su resolución, de acuerdo a la casuística encontrada en este quinquenio, influyendo en dichos exámenes el tipo de ilícito penal de acuerdo al índice delincuencial de cada uno de ellos, de lo cual dependió el tipo de muestra genética con la que se trabajó (sangre, semen, huesos, pelos, etc.), plasmándose los resultados en pericias genético-forenses, en las cuales se observó que para constituirse en pruebas científicas idóneas para el proceso penal,

16 Robert A. Day. Cómo escribir y publicar trabajos científicos. Segunda edición. Washington D.C.: OPS (Publicación Científica 550), 1966, pp. 44-45. 
tuvieron que estar supeditadas a una correcta colección de $\mathrm{ADN}$ y a una indemne cadena de custodia. ${ }^{17}$

De nuestra realidad se infiere que el aumento de esta demanda pericial se debe principalmente al incremento de la criminalidad, la cual se da fundamentalmente por un problema social que tiene una génesis económica ligada a una degradación de la escala axiológica debido a la pérdida de valores intrínsecos de una sociedad que debiera regirse por principios éticos, denotando esto una relación siempre actual entre la ética y la economía, ${ }^{18}$ todo ello también acompañado por una afectación de la sociedad con psicopatologías, evidenciada por la conducta atípica de su delincuencia, dado que el entorno social se nutre de la actividad psíquica. ${ }^{19}$ Se agudiza este problema aún más por una educación deficiente.

Esta situación por la que atraviesa nuestro país en la actualidad se ve evidenciada por el incremento geométrico de ilícitos penales, especialmente en los casos de delitos contra el patrimonio (robo), delitos contra la vida, el cuerpo y la salud (homicidio) y sobre todo en delitos contra la libertad (violación sexual), que en los últimos años han superado a otros delitos, como se ha encontrado en los resultados estadísticos.

\section{DISCUSIÓN}

De los resultados se puede evidenciar que en nuestro país del año 2006 al 2012 hubo un aumento del número de casos forenses que han requerido exámenes genéticos para su resolución, de acuerdo a la casuística encontrada en el sexenio investigado, influyendo en dichos exámenes, el tipo de ilícito penal de acuerdo al índice delincuencial de cada uno de ellos, de lo cual dependió el tipo de muestra genética con la que se trabajó (sangre, semen, huesos, pelos, etc.), plasmándose aquello en pericias genético-forenses, en las cuales se observó que para constituirse en pruebas científicas idóneas para el proceso penal, tuvieron que estar supeditadas a que el Laboratorio de Biología Molecular (ADN) de la DIREJCRI PNP deba contar con un abastecimiento logístico eficiente, procedimientos idóneos y protocolos estandarizados conjuntamente con recursos humanos altamente especializados para desarrollar una correcta prueba del ADN.

Este trabajo de investigación se inició con el estudio de los factores humanos y logísticos que intervienen en la prueba de $\mathrm{ADN}$ tanto en el laboratorio como en la escena

17 Raúl Quintanilla R. Colección de ADN y cadena de custodia en la genética forense, su importancia en la investigación criminal y sus implicancias jurídicas en el proceso penal peruano. Lima: Universidad Nacional Mayor de San Marcos, Facultad de Derecho y Ciencia Política, 2008.

18 Eduardo Schmidt. Ética y negocios para América Latina. Lima: Universidad del Pacífico - OXY (Biblioteca Universitaria), 1995.

19 Guy Rocher. Introducción a la sociología general. Barcelona: Herder, 1979. 
del crimen en el análisis de cada una de las pericias genéticas realizadas en los laboratorios de biología molecular y $\mathrm{ADN}$ de las instituciones tutelares del Estado que tienen la función de investigar los delitos, como la Dirección Ejecutiva de Criminalística de la Policía Nacional del Perú y el Instituto de Medicina Legal y Ciencias Forenses del Ministerio Público.

Cabe remarcar que la estandarización de la técnica de colección de ADN en el lugar de los hechos y la implementación logística de un laboratorio de biología molecular y genética con tecnología de punta como el contar con una base de datos de ADN de uso criminal son de vital importancia en la genética forense, y conllevarían una investigación criminal exitosa al identificar plenamente a las personas involucradas en el proceso penal con elementos probatorios de una validez científica indubitable y sobre todo con el criterio de oportunidad que da la automatización del cotejo de muestras genéticas dentro del contexto de implementación paulatina del código procesal penal de 2004, que se inició el 01 de julio de 2006 en el distrito judicial de Huaura, prosiguiendo gradualmente hasta su conclusión el 01 de diciembre de 2014 en Lima y Callao, por ser los distritos judiciales con mayor carga procesal. A este nuevo modelo penal que se implementa en el país, se le plantea el reto de la celeridad del proceso, con plazos pre-establecidos en la investigación criminal que deben de respetarse de manera irrestricta para obtener la eficacia que la población demanda de la justicia penal.

El éxito de este nuevo modelo penal eficiente y oportuno, que plantea el Código Procesal Penal de 2004, depende básicamente de la plena disponibilidad, indemnidad y garantía de medios de prueba científicos y contundentes, constituidos en el campo biológico por el examen de ADN o DNA fingerprint.

Tenemos también como resultados a discutir por un lado que la tecnología del ADN aplicada al campo forense con fines de identificación humana puede tener y de hecho posee un muy elevado índice de certeza (99,99\%), y por ende no se duda de su validez científica. Un cuestionamiento a dicha prueba puede darse no en la prueba misma, sino en las etapas previas al examen genético y que también son preocupación en el presente trabajo de investigación, es decir, en la colección de ADN y en la cadena de custodia, en las cuales se puede haber llevado a cabo errores involuntarios o premeditados; pudiendo sucederse una contaminación con $\mathrm{ADN}$ extraño por una mala manipulación.

Por otro lado, se ha observado que una homologación o cotejo automatizado en un sistema alfanumérico de perfiles genéticos almacenados en una base de datos permite una rápida comparación y por ende una rápida identificación genética de criminales, sobre todo en hechos de sangre o delitos donde media violencia, por lo que el no contar con esta tecnología implica contar finalmente con una evidencia extemporánea y por lo tanto con una prueba inconsistente, lo cual viciará el proceso, y si no es advertido a tiempo, dará 
lugar a una sentencia errónea, condenándose a un inocente o eximiendo a un culpable, es decir, produciendo una mala administración de justicia.

En el contexto de homogeneizar la legislación y la operatoria judicial de nuestra región periférica con los estándares internacionales de derechos humanos de los países centrales, el Perú realiza en la actualidad denodados esfuerzos por implementar un modelo penal moderno, ágil y eficiente a través de un nuevo código procesal, cuyo fundamento probatorio y que sustenta todo el procedimiento penal es el peritaje técnico-científico.

De la investigación realizada se puede desprender que existen técnicas, procedimientos y metodologías compartidas por los peritos que conforman el cuerpo científico de la Policía Nacional del Perú y del Instituto de Medicina Legal y Ciencias Forenses del Ministerio Público, tanto en la fase previa que implica la colección de evidencias y cadena de custodia como en la fase de laboratorio, y es en esta última fase donde por los resultados del presente trabajo de investigación se colige que esta labor de identificación genética con fines forenses aun adolece del retraso en la homologación de perfiles, lo que trae ineficiencia y por lo tanto impunidad, no siendo lo más apto para la realización de trabajos forenses ni para la finalidad de dar confianza al usuario del sistema penal que ofrece el Estado, es decir, al ciudadano como primera ratio de la maquinaria judicial, para quien se sustenta el proceso penal.

La implementación de una BD-ADN-F sumada a técnicas de laboratorio genéticoforenses acreditadas por organismos de certificación de procedimientos y de laboratorios, competentes internacionalmente, permitirán elevar la confianza de la población y de los operadores del Derecho hacia los servicios forenses que prestan las instituciones tutelares del Estado que tienen dicha función. Un ejemplo de ello es el Laboratorio de Genética y Biología Molecular de la Dirección Ejecutiva de Criminalística de la Policía Nacional del Perú, que se encuentra acreditada por el Grupo Iberoamericano de Trabajo en ADN (GITAD), liderado por José Antonio Lorente Acosta, M. D. y Ph. D, profesor asociado de medicina forense y director del Laboratorio de Identificación Genética de la Universidad de Granada (España), pionero en Europa en el análisis de ADN con fines forenses. Dicha certificación es revalidada periódicamente a través de homologaciones de contramuestras de la misma evidencia genética que se envían desde el Perú a laboratorios de referencia donde se trabajan paralelamente y cuyos resultados deben coincidir con la obtención de los mismos perfiles de ADN en los laboratorios de cotejo, indicativo de conformidad y, por lo tanto, de la calidad total de las pruebas de $\mathrm{ADN}$ realizadas en el Perú.

20 Raúl Quintanilla R. Responsabilidad penal y reparación civil del Estado por crimenes de lesa humanidad a las víctimas de la violencia politica en la sociedad peruana de albores del siglo XXI. Ponencia presentada al X Congreso Iberoamericano y XVIII Latinoamericano de Derecho Penal y Criminología. Bogotá D. C: Universidad Nacional de Colombia, 2006. 


\section{ORDENAMIENTO Y ANÁLISIS DE DATOS}

Todos los datos utilizados son evaluados y clasificados en orden de importancia, de acuerdo a la hipótesis que trata de brindar sustentadamente las posibles soluciones a la problemática planteada, dada la trascendencia del tema dentro del contexto de reforma del sistema penal peruano en general y de la investigación criminal en particular, como parte conformante y primigenia de todo el proceso penal, de la cual depende el éxito o fracaso de dicho procedimiento.

Para ello, el análisis y discusión de los resultados de la investigación se desarrollarán a través de los siguientes rubros, que son los pilares del presente trabajo:

\section{El grado de confiabilidad forense de las bases de datos de ADN de uso forense}

Del análisis de la información vertida por las instituciones oficiales de países que utilizan sistemas automatizados de identificación genética y que colaboraron con el presente estudio como Australia, Colombia, Chile, España y México, se aprecia que los peritos genetistas que administran los correspondientes bancos y bases de datos de ADN de uso criminal, presentan como opinión consolidada un muy alto grado de confiabilidad de estos instrumentos tecnológicos de genética forense, presentando como respuestas la alternativas de regular, bueno y muy bueno. Estos resultados se complementan con los índices positivos en general de eficacia en las investigaciones criminales en dichos sistemas judiciales.

\section{El incremento de eficacia de la investigación criminal con el uso de bases de datos de ADN}

Del análisis de la información vertida por las instituciones oficiales de países que utilizan sistemas automatizados de identificación genética y que colaboraron con el presente estudio como Australia, Colombia, Chile, España y México se aprecia que los peritos genetistas que administran bases de datos de ADN criminales, al analizar las alternativas múltiples del cuestionario, más de la mitad de estos funcionarios presentan como opinión consensuada que el uso de bancos y bases de datos de $\mathrm{ADN}$ criminal han permitido cotejos genéticos de muestras biológicas dubitadas halladas en la escena del crimen con los perfiles genéticos almacenados en la BD-ADN, eligiendo más del $80 \%$ de profesionales especializados las alternativas de alta y muy alta, lo cual indica en los casos de existencia de evidencias genéticas un incremento significativo de la eficacia de las diligencias preliminares durante la fase de investigación preparatoria de un sistema penal acusatorio moderno.

El cotejo de evidencias genéticas de la escena del crimen con las almacenadas en la base de datos de ADN de uso forense

De los cotejos genéticos de muestras biológicas dubitadas halladas en la escena del crimen o lugar de los hechos, como sangre, semen, cabellos, pelos y otros fluidos biológicos 
de los cuales se puede extraer ADN para realizar los correspondientes perfiles genéticos en el Laboratorio de $\mathrm{ADN}$, se concluye que en la actualidad los países que cuentan con BD$\mathrm{ADN}$ de uso criminal los realizan de mejor manera y más rápidamente, o de igual manera y más rápidamente. Esto indica un incremento significativo de la eficacia de las diligencias preliminares durante la fase de investigación preparatoria de sus modernos sistemas penales.

La aplicación del análisis de las variables de estudio y su aplicación al resultado de las encuestas

La base de datos de ADN de uso forense, considerada variable independiente en la presente investigación, aún no tiene un desarrollo en nuestro país a pesar de que existen ofrecimientos del FBI a través de la Embajada de los EE.UU. en Lima de entregar al Perú en calidad de donación el software del sistema CODIS, previa firma de un convenio interinstitucional entre las entidades oficiales de orden y seguridad de ambos países, como es el caso ejemplificador de la Universidad de Granada de España, a través del Dr. Ph. D. José Antonio Lorente Acosta, que tras la firma del respectivo convenio concede a la DIREJCRI PNP la administración total del software "Programa DNA - PROKIDS PERU” (base de datos), a fin de guardar la información genética de niños en riesgo y/o sus familiares directos, de conformidad a la legislación vigente, legislación que en nuestro país, en el caso de una BD-ADN de uso criminal, lamentablemente aún no existe, razón por la que no es factible todavía desarrollar la implementación y ampliación de esta BD-ADN.

Esta limitante al trabajo de investigación, que no permitió analizar la variable independiente en nuestro país, motivó el recurrir a 16 países que sí cuentan desde hace un tiempo con estos sistemas automatizados de identificación genética con fines forenses, solicitándose información especializada, a través de sus respectivas embajadas en la ciudad de Lima, siendo estos países los siguientes: Estados Unidos, Reino Unido, Portugal, España, Francia, Australia, Argentina, Chile, Uruguay, Brasil, Colombia, Venezuela, Panamá, Costa Rica, México y Canadá.

De los 16 países requeridos, solo 5 presentaron disponibilidad de colaboración para poder contrastar la hipótesis de la investigación, la cual plantea que "si la genética forense peruana cuenta con una BD-ADN, entonces se incrementará la eficacia de la identificación humana en delitos con evidencias genéticas optimizándose las diligencias preliminares de la investigación preparatoria del proceso penal acusatorio peruano".

De la información brindada por funcionarios especializados de instituciones oficiales de Australia, Colombia, Chile, España y México, que gestionan sus respectivas BD-ADN de uso criminal, se plantea la necesidad de que la implementación de esta BD-ADN-F, aparte de contar con un Laboratorio y tecnologías forenses de ADN acreditadas por 
organismos internacionales de la especialidad de reconocido prestigio, deben tener también procesos personalizados y estandarizados a nivel nacional para cada país en particular.

Luego de analizar los datos vertidos y la opinión especializada de los funcionarios oficiales de las instituciones que gestionan las BD-ADN de uso forense en estos países, se pudo corroborar la hipótesis formulada en este trabajo de investigación, validándose la misma con la realidad genético-forense de dichos países. Así, se reafirma la propuesta de que en el Perú la implementación de una BD-ADN-F (variable independiente) es muy importante para la optimización de la investigación preparatoria del actual proceso penal, lo cual implica el ahorro de tiempo, recursos humanos, económicos y logísticos.

En el estudio de la variable dependiente identificación criminalistica por ADN nacional, se pudo encontrar que fundamentalmente son tres (03) los factores que intervienen en la determinación de la calidad de la genética forense peruana:

- Factores humanos o profesionales.

- Factores tecnológicos o logísticos.

- Factores externos o ambientales.

En lo que se refiere a la variable interviniente nuevo proceso penal peruano, se observó un incremento significativo del índice delincuencial en general y de los delitos donde media violencia, en particular en donde se dispone de evidencias genéticas; por lo tanto, se colige la necesidad de dotarla de un sistema informatizado que acelere las diligencias preliminares de la fase de investigación preparatoria, al observarse un déficit en la tecnología del ADN, tanto en la Dirección Ejecutiva de Criminalística de la Policía Nacional del Perú como en el Instituto de Medicina Legal y Ciencias Forenses del Ministerio Publico.

La labor interinstitucional del Ministerio Público y la Policía Nacional del Perú y su importancia en el nuevo modelo penal

Una discusión aparte merece en el presente acápite un factor que no interviene directamente en la investigación, pero que posee una importancia político- estratégica para el éxito del nuevo sistema penal propuesto por el Código Procesal Penal de 2004, el cual está constituido por aquella relación interinstitucional que es concomitante a toda investigación criminal. Nos referimos a los pesquisas y peritos de la Policía Nacional y a los profesionales del Ministerio Público, tanto jurídicos (fiscales) como técnico-científicos (peritos del Instituto de Medicina Legal y Ciencias Forenses), con los cuales aun no se da una plena coordinación que conlleve a apuntar a un solo norte en el aspecto técnico de la investigación criminalística; al contrario, existen roces innecesarios por un incomprensible celo profesional, por la creencia errónea de una superposición o duplicidad funcional. 
Al respecto, los roles están bien definidos por el Decreto Legislativo No 957 - CPP 2004, el cual, taxativamente en su artículo 67 numeral 1, señala que " la Policía Nacional en función de investigación, debe, inclusive por propia iniciativa, tomar conocimiento de los delitos y dar cuenta inmediata al Fiscal, sin prejuicio de realizar las diligencias de urgencia e imprescindibles para impedir sus consecuencias, individualizar a sus autores y partícipes, reunir y asegurar los elementos de prueba”.

Si bien el espíritu del Código Procesal Penal de 2004 espera que la Policía Nacional ponga inmediatamente la denuncia en conocimiento del Ministerio Público, en la práctica aquella realiza una primera investigación de los hechos delictivos, y si considera que el delito efectivamente se cometió, remite el caso al Ministerio Público; de lo contrario, lo archiva. En ese orden de ideas, la Policía Nacional está encaminada a que sea el Ministerio Público el que tome las decisiones jurídicas que son fundamentales en los casos penales en investigación.

La intimidad personal como derecho fundamental que presuntamente es vulnerado por la base datos de $\mathrm{ADN}$ de uso forense

Conforme a los estatutos jurídicos generalmente reconocidos, las huellas de ADN son datos personales y esa consideración nos impone analizar, de acuerdo a esa naturaleza, los mecanismos de protección que se han previsto en la normativa de los países que cuentan con BD-ADN-F. Ello nos permitirá una adecuada calificación de los datos de ADN dentro de las distintas categorías de datos, para luego determinar quiénes pueden tratar información de este tipo con finalidad de investigación e identificación y cómo sería lícito realizar el tratamiento. En ese orden de ideas, si los datos de perfiles de $\mathrm{ADN}$ son datos personales habría que ver si son datos públicos o datos sensibles, pues la doctrina contemporánea los cataloga como datos sanitarios, dentro de los cuales se consideran tanto datos médicos como datos genéticos, vinculándose así en un mismo concepto los datos relacionados con la salud y los de la información genética. Pero establecer que todos los datos genéticos son sanitarios sería algo aventurado, pues solo son tales los que corresponden a aquella parte del ADN llamada codificante (que representa el 10\% de la información del ADN), pero el ADN no codificante (el $90 \%$ restante), conocido como "ADN basura", no tiene tal calidad, ${ }^{21}$ y esto se explica al considerar que las secuencia repetitivas y características de ADN que se encuentra dentro del $\mathrm{ADN}$ No Codificante de cada persona y que son únicas respecto de todas las demás perfiles de ADN, no constituyen datos sanitarios ya que no revelan por sí mismos ninguna característica sobre el estado de salud de una persona y tampoco son propiamente genéticos, al ser solamente un conjunto de secuencias no susceptibles de ser

21 Carlos Reusser M. Perfiles de ADN y bases de datos: los desafios de la autodeterminación informativa de Europa. Chile: Centro de Estudios en Derecho Informático, Universidad de Chile. 
calificadas como genes, aun cuando integrado a una base de datos personales pueda revelar la identidad; por ello no podría considerárseles dentro del e status jurídico de datos sanitarios al tratar de definir su naturaleza jurídica, ya que no brindan información alguna sobre las características físicas o fenotípicas del individuo.

Sin embargo, dada su naturaleza, podemos sostener con sólidos fundamentos que aun cuando los datos de perfiles de ADN no son datos sensibles, se encuadran como una categoría especial de datos en tanto constituyen un medio de identificación de carácter general. Por ello, para que sea posible su tratamiento se requiere autorización legal de los Estados, ya que debemos considerar que una base de perfiles de datos de ADN de individuos de una comunidad a los cuales pueda ligarse otra información como los nombres y domicilio legal se puede entender como un ejemplo de eficacia identificatoria, lo cual colisionaría con el pensamiento constitucional de Estado de Derecho, ya que podría constituir un modelo de Estado policiaco donde sería factible realizar seguimientos casi perfectos de las personas a través de la huella de $\mathrm{ADN}$, destruyendo la institución constitucional de autodeterminación informativa.

Como vemos existe una gran potencialidad en las bases de datos de $\mathrm{ADN}$ forense que implica se conjuguen aspectos referidos a cuestiones jurídicas (leyes), de genética forense, probabilística e incluso tecnología informática, en donde en dicha regulación se establezca a dicha base de datos como una herramienta eficaz en la lucha contra la criminalidad, ya que si no se estableciera en esas bases de datos ningún límite a la inclusión y permanencia de perfiles y, en su caso, la conservación de las muestras, se vulneraría el derecho a la intimidad y a la protección de datos; ${ }^{22}$ por ese motivo, la legislación peruana que cree la BD-ADN-F debe garantizar el respeto irrestricto al derecho a la intimidad personal y demás derechos constitucionales.

\section{CONCLUSIONES}

El propósito del presente trabajo de investigación ha sido aproximarnos al estudio del régimen jurídico de protección de datos aplicable al almacenamiento de perfiles de ADN. Esto es relevante en la medida que la eficacia de dicho intercambio está vinculada a la obtención de una prueba pericial de $\mathrm{ADN}$ que sea admisible en un proceso penal y que sea lo más fiable posible; por ello, debe ser una prueba que se haya obtenido lícitamente, con la máxima consideración a los derechos fundamentales, y en el caso de tratamiento de perfiles genéticos en una BD-ADN-F, con el respeto al derecho de intimidad personal. En ese sentido podemos enumerar tres conclusiones importantes:

22 María Cabezudo B. Las bases de datos policiales de ADN. Madrid: Dykinson S. L., 2013. 
1. Uno de los aspectos medulares para el mejoramiento y rapidez de la identificación humana que realiza la genética forense peruana se refiere a la creación de una BDADN de uso criminal, coligiéndose esta afirmación a partir del análisis y discusión de los resultados, luego de contrastar la hipótesis con la realidad en países líderes en genética forense como Australia, Colombia, Chile, España y México; y viendo en el caso peruano que existe una falencia en el criterio de oportunidad en la resolución de casos brindada por los actuales laboratorios de genética forense del Estado que cumplen función investigativa, por lo que los perfiles de ADN obtenidos de la escena del crimen no tiene mayor utilidad al no poderse cotejar con otros conocidos que permitan la identidad del delincuente de manera rápida.

2. Del análisis efectuado se infiere la importancia de que este BD-ADN sea administrado por la Dirección Ejecutiva de Criminalística de la Policía Nacional del Perú, por un tema de pragmatismo y operatividad, ya que este ente es el que realiza en primera instancia la investigación criminal y requiere cotejar muestras problema con muestras patrón de manera rápida, como por ejemplo se dan en los cotejos automatizados de huellas papiloscópicas, balísticas y faciales respectivamente, siempre y cuando se de en la Policía Nacional una verdadera e integral reforma policial, donde se valore no solo el tecnicismo de sus procedimientos, sino sobre todo la ética policial y deontología forense reflejadas en el profesionalismo de sus hombres.

3. Se requiere en el Perú la dación de una ley de creación de una BD-ADN de uso forense que permita registrar perfiles genéticos de población relevante para la investigación criminal y para la búsqueda de desaparecidos, donde se especifiquen consideraciones técnicas y jurídicas que garanticen el respeto irrestricto a libertades fundamentales y derechos constitucionales, como la intimidad personal de los integrantes de dicha población, que permita una gestión eficiente de dicha BD-ADN-F y que coadyuve a las investigaciones de delitos con evidencias biológicas, en el contexto del nuevo proceso propuesto por el Código Procesal Penal de 2004. 


\section{REFERENCIAS}

- Babbie, E. R. The practice of social research. California: Wadsworth, 1979.

- Bernal T., César. Metodología de la investigación para administración, economía, humanidades y ciencias sociales. Bogotá D. C.: Pearson Educación, 2010.

- Bernath, Viviana. La identidad. Historias reales del ADN. Buenos Aires: Grupo Editorial Planeta, 2007.

- Cabezudo B., María. Las bases de datos policiales de ADN. Madrid: Dykinson S. L., 2013.

- Dankhe, G. L. Investigación y comunicación. México: McGraw-Hill, 1986.

- Day, Robert A. Cómo escribir y publicar trabajos científicos. Segunda edición. Washington D.C.: OPS (Publicación Científica 550), 1966.

- Hernández S., Roberto. Metodología de la investigación. Bogotá D.C.: McGraw-Hill, Interamericana, 1997.

- Kerlinger, F. Enfoque conceptual de la investigación del comportamiento. México: Interamericana, 1990.

- Paz K., Paola. Problemática legal generada por la falta de regulación respecto al manejo de bases de datos genéticos de uso forense. Tesis para optar el título de Magíster en Biociencias y Derecho. Bogotá D.C.: Universidad Nacional de Colombia, 2012.

- Quintanilla R., Raúl. La prueba genética en el proceso penal, su idónea colección de ADN y cadena de custodia en la investigación criminal y sus implicancias jurídicas en el Nuevo Código Procesal Penal. Ponencia presentada al XX Congreso Latinoamericano, XII Iberoamericano y V Nacional de Derecho Penal y Criminología. Lima: Universidad Nacional Mayor de San Marcos, 2008.

- Quintanilla R., Raúl. Responsabilidad penal y reparación civil del Estado por crimenes de lesa humanidad a las victimas de la violencia politica en la sociedad peruana de albores del siglo XXI. Ponencia presentada al X Congreso Iberoamericano y XVIII Latinoamericano de Derecho Penal y Criminología. Bogotá D. C: Universidad Nacional de Colombia, 2006.

- Quintanilla R., Raúl. Colección de ADN y cadena de custodia en la genética forense, su importancia en la investigación criminal y sus implicancias juridicas en el proceso penal peruano. Lima: Universidad Nacional Mayor de San Marcos, Facultad de Derecho y Ciencia Política, 2008. 
- Quintanilla R., Raúl. Factores de la inspección criminalística que determinan la calidad de la investigación de la escena del crimen y su importancia en el nuevo modelo procesal penal peruano. Tesis para optar el grado de Magíster. Lima: Universidad Nacional Mayor de San Marcos, Escuela de Postg rado, Unidad de Post Grado en Derecho, 2011.

- Ramírez E., Ramón. Proyecto de investigación. Cómo se hace una tesis. Lima: Fondo Editorial AMADP, 2010.

- Reusser M., Carlos. Perfiles de ADN y bases de datos: los desafios de la autodeterminación informativa de Europa. Chile: Centro de Estudios en Derecho Informático, Universidad de Chile.

- Rocher, Guy. Introducción a la sociología general. Barcelona: Herder, 1979.

- Schmidt, Eduardo. Ética y negocios para América Latina. Lima: Universidad del Pacífico OXY (Biblioteca Universitaria), 1995.

- Selltiz, C.; M. Jahoda; M. Deutsch y S. W. Cook. Métodos de investigación en las relaciones sociales. Madrid: Ediciones Rialp, 1965.

- Toffler, Alvin. La tercera ola. Bogotá D. C.: Plaza \& Janés, 1981.

- Zorrilla, S. y M. Torres. Guía para elaborar la tesis. México: Editorial McGraw-Hill, 1993. 